\title{
Physico-Geometrical Interpretation of the Kinetic Behavior of the Thermal Dehydration of $\beta$-Maltose Monohydrate
}

Takahiro Okazaki and Nobuyoshi Koga*

Department of Science Education, Graduate School of Education, Hiroshima University, 1-1-1 Kagamiyama, Higashi-Hiroshima 739-8524, Japan

\section{Contents}

S1. Sample Characterization .s2

Figure S1. Appearance of the sample particles: (a) optical microscopy and (b) SEM. .......................................s2

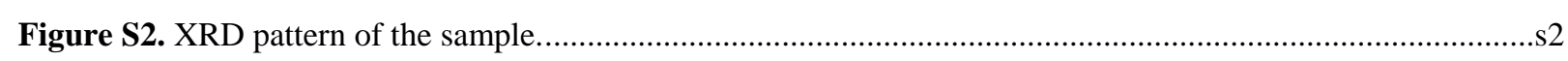

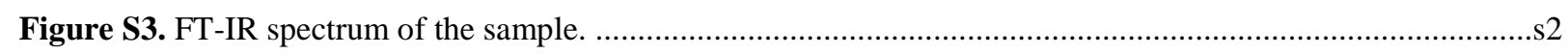

Table S1. Assignment of the characteristic IR absorption peaks.......................................................................s2

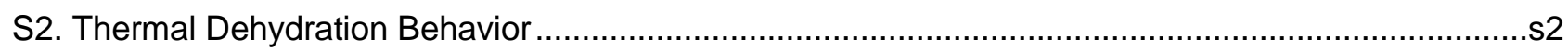

Figure S4. Microscope views of the dome produced by heating $\beta$-maltose monohydrate to $403 \mathrm{~K}$ at a $\beta$ of $5 \mathrm{~K}$ min $^{-1}$ under flowing $\mathrm{N}_{2}$ gas: (a) top view, (b) bottom view, and (c) cross section view.

Figure S5. Microscopic views of the sample in the pan obtained by heating to different temperatures at a $\beta$ of $0.5 \mathrm{~K}$ $\min ^{-1}$ under flowing $\mathrm{N}_{2}$ gas: (a) $395 \mathrm{~K}$ (just after the completion of thermal dehydration), and (b) $403 \mathrm{~K}$ (when the dome is formed).

Figure S6. Typical TG-DTG curves for the thermal dehydration of $\beta$-maltose monohydrate at $391 \mathrm{~K}$ under flowing $\mathrm{N}_{2}$ gas at a rate of $80 \mathrm{~cm}^{3} \mathrm{~min}^{-1}$.

S3. Glass Transition of Anhydrous Maltose .53

Figure S7. TG-DTA curves for the cooled anhydride $\left(m_{0}=4.72 \pm 0.02 \mathrm{mg}\right)$ produced by the isothermal dehydration of $\beta$-maltose, recorded at different $\beta$ values.

\footnotetext{
* Corresponding author. E-mail: nkoga@hiroshima-u.ac.jp
} 


\section{S1. Sample Characterization}
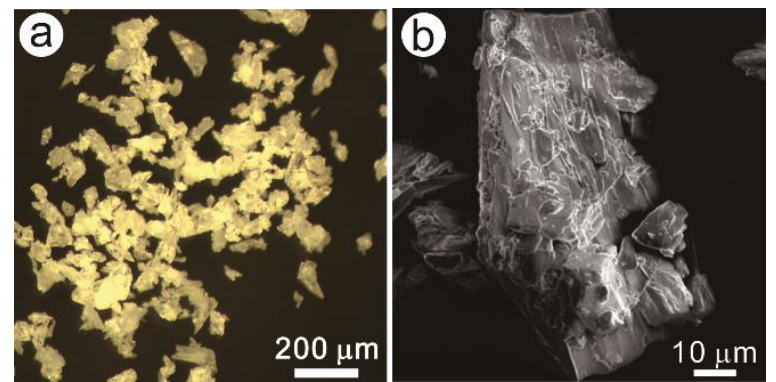

Figure S1. Appearance of the sample particles: (a) optical microscopy and (b) SEM.

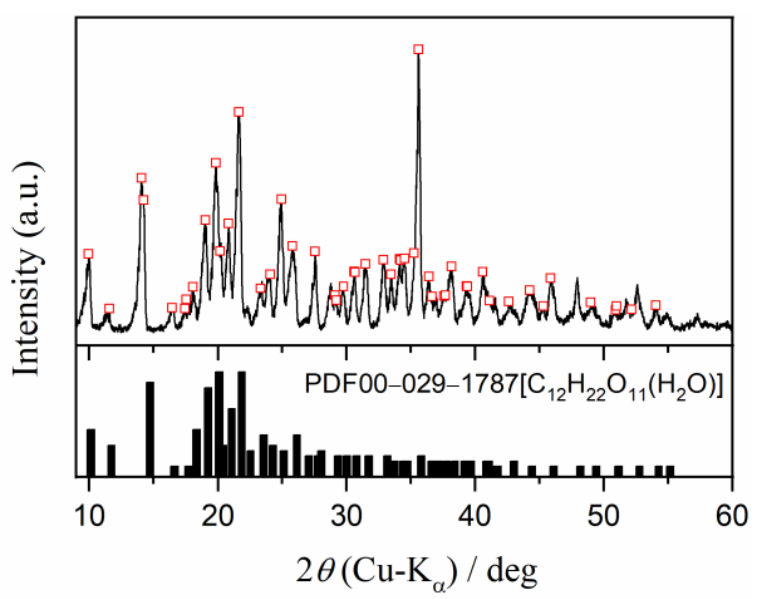

Figure S2. XRD pattern of the sample.

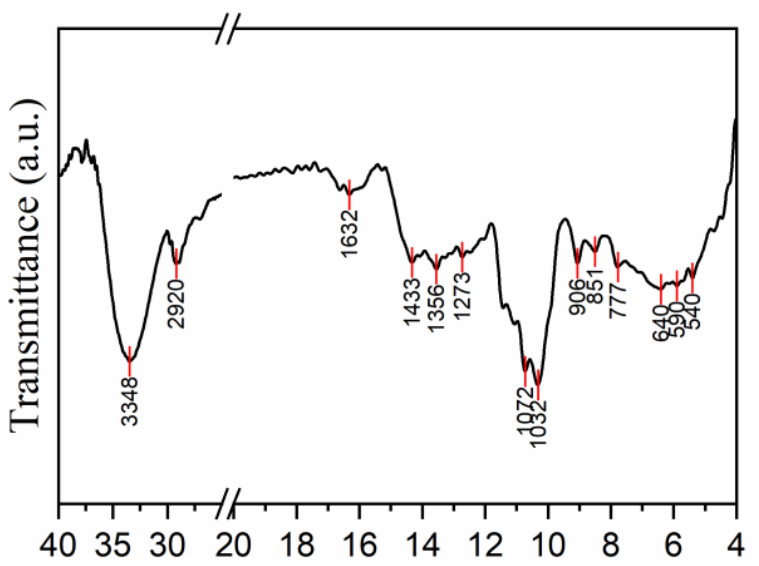

Wavenumber $/ 10^{2} \mathrm{~cm}^{-1}$

Figure S3. FT-IR spectrum of the sample.
Table S1. Assignment of the characteristic IR absorption peaks. ${ }^{41}$

\begin{tabular}{|c|c|}
\hline Wavenumber $/ \mathrm{cm}^{-1}$ & Assignment \\
\hline $3700-2850$ & $v \mathrm{OH}, v_{\mathrm{s}} \mathrm{CH}, v_{\mathrm{as}} \mathrm{CH}$ \\
\hline 1676 & $\delta \mathrm{H}-\mathrm{O}-\mathrm{H}$ \\
\hline 1460 & $\delta \mathrm{CH}_{2}+\delta \mathrm{CCH}$ \\
\hline 1434,1273 & $\delta \mathrm{OCH}+\delta \mathrm{CCH}$ \\
\hline 1360 & $\delta \mathrm{CCH}+\delta \mathrm{OCH}+\rho \mathrm{CH}$ \\
\hline 1077 & $\delta \mathrm{CO}+v \mathrm{CC}$ \\
\hline 1038 & $v \mathrm{CO}+\rho \mathrm{CH}$ \\
\hline 998, 907 & $\begin{array}{l}\nu \mathrm{CO}+\nu \mathrm{CCH}+\rho \mathrm{CH} \text { of } \\
\text { glycosidic bridge }\end{array}$ \\
\hline
\end{tabular}

\section{S2. Thermal Dehydration Behavior}
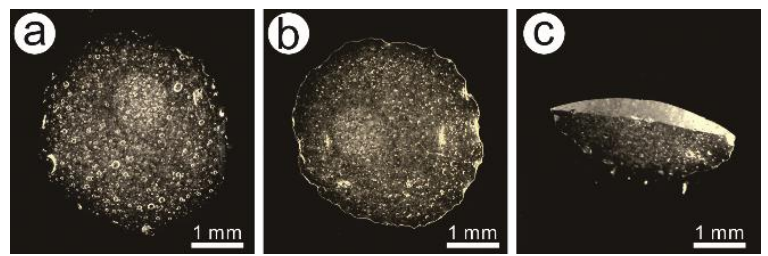

Figure S4. Microscopic views of the dome produced by heating $\beta$-maltose monohydrate to $403 \mathrm{~K}$ at a $\beta$ of 5

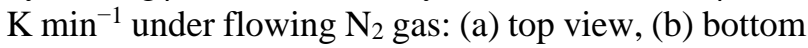
view, and (c) cross section view.
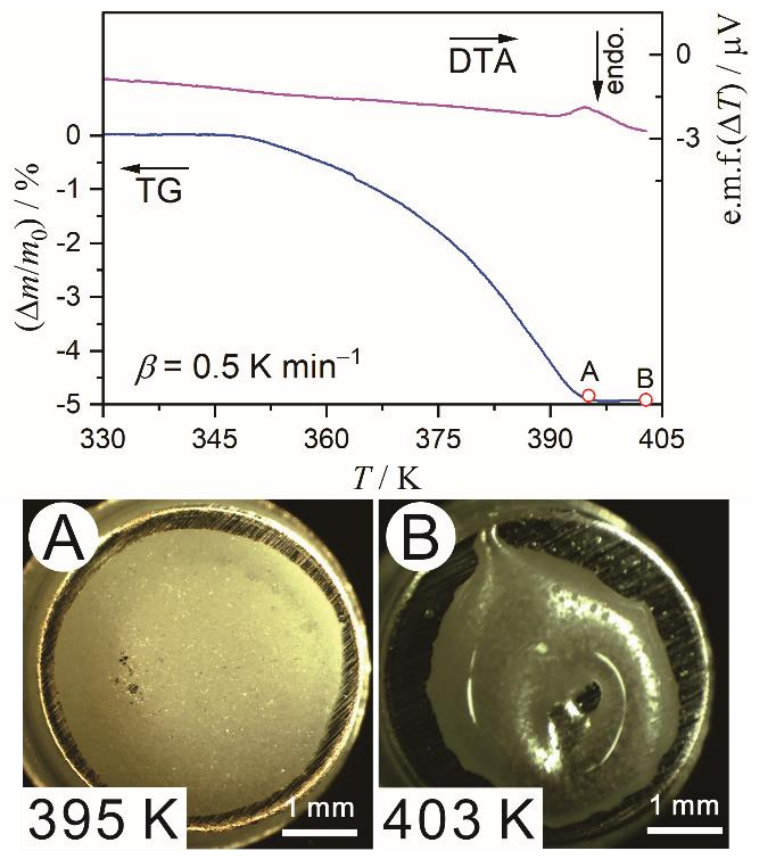

Figure S5. Microscopic views of the sample in the pan obtained by heating to different temperatures at a $\beta$ of $0.5 \mathrm{~K} \mathrm{~min}^{-1}$ under flowing $\mathrm{N}_{2}$ gas: (a) $395 \mathrm{~K}$ (just after the completion of thermal dehydration), and (b) $403 \mathrm{~K}$ (when the dome is formed). 


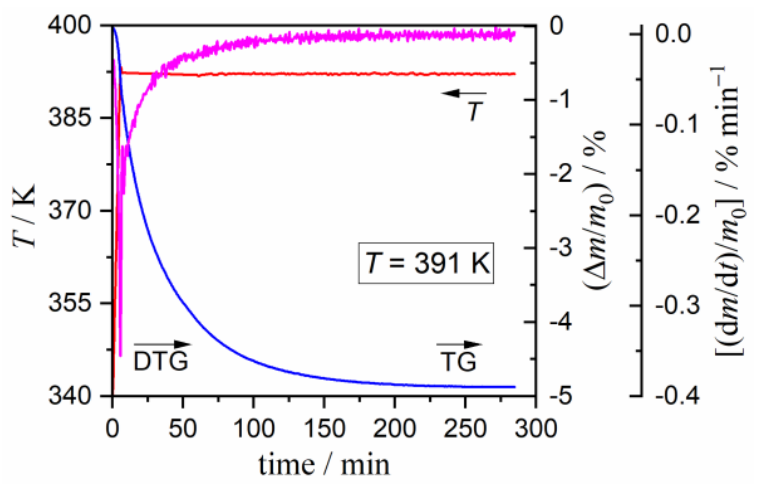

Figure S6. Typical TG-DTG curves for the thermal dehydration of $\beta$-maltose monohydrate at $391 \mathrm{~K}$ under flowing $\mathrm{N}_{2}$ gas at a rate of $80 \mathrm{~cm}^{3} \mathrm{~min}^{-1}$.

S3. Glass Transition of Anhydrous Maltose

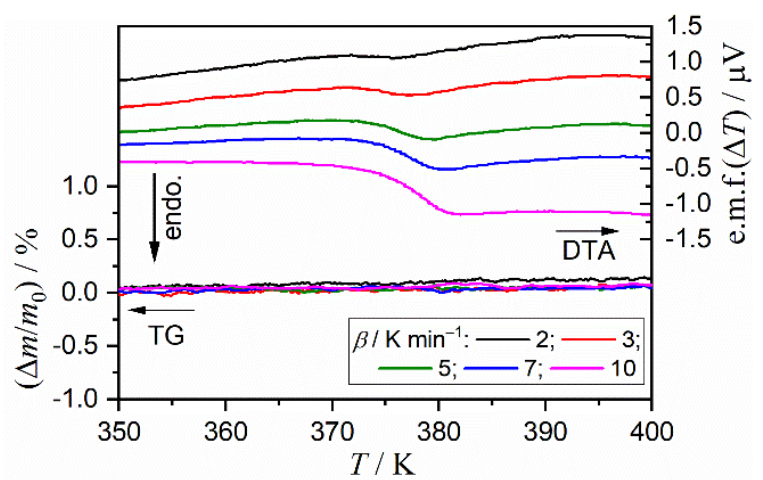

Figure S7. TG-DTA curves for the cooled anhydride $\left(m_{0}=4.72 \pm 0.02 \mathrm{mg}\right)$ produced by the isothermal dehydration of $\beta$-maltose monohydrate, recorded at different $\beta$ values. 